\title{
ISOLATED TUBERCULOSIS OF NAVICULAR BONE: A CASE REPORT
}

\author{
Indudhara P. B1, Harish Pai 2 , V. V. Yenni ${ }^{3}$
}

\section{HOW TO CITE THIS ARTICLE:}

Indudhara P. B, Harish Pai, V. V. Yenni. "Isolated Tuberculosis of Navicular Bone: A Case Report". Journal of Evolution of Medical and Dental Sciences 2015; Vol. 4, Issue 40, May 18; Page: 7071-7073,

DOI: $10.14260 /$ jemds/2015/1027

\begin{abstract}
Skeletal tuberculosis rare in foot. Bones generally involved are the spine (Dorsolumbar), skull, shoulder girdle and hip bones. Involvement of the foot is infrequent. Very rare in navicular bone. A female of 23 years presented with swelling and pain in of right foot. X-ray showed lytic lesion with sclerotic margins. Biopsy was done and histopathological diagnosis of tuberculosis was made.
\end{abstract}

KEYWORDS: Tuberculosis, Navicular bone, Rare.

INTRODUCTION: Skeletal tuberculosis is a very rare disease comprising 1-3\% of the total population of tubercular patients. ${ }^{1}$ Tuberculosis of the foot and ankle is an uncommon presentation of skeletal tuberculosis. The ability to mimic other disorders clinically and on radiographs, leads to diagnostic and therapeutic delays. ${ }^{2}$

Osteoarticular tuberculosis makes up $<3 \%$ of the cases of extra-pulmonary tuberculosis, of which about $10 \%$ involve the foot and ankle region. Bones generally involved are the spine (Dorsolumbar), skull, shoulder girdle and hip bones. Involvement of the foot is infrequent ${ }^{3}$. Isolated bony involvement in navicular bone is even more-rare.

CASE REPORT: A young lady of 23 years of age, presented with swelling and pain in the right foot since 6 months. On examination solitary, firm, ill-defined swelling approximately measuring $2 \mathrm{x} 2 \mathrm{~cm}$ was noted. Laboratory investigations showed increased leucocytes, elevated Erythrocyte Sedimentation Rate and high Adenosine De Aminase levels. Radiological imaging (Figure 1) showed a lytic lesion in navicular bone in right foot. On pathological examination, C-arm guided aspiration cytology revealed giant cell lesion. Bony biopsy (Figure 2) showed bony spicules with granuloma consisting of epitheloid cells, langhans giant cells and lymphocytes. Patient has been put on antitubercular treatment and is making good recovery.

DISCUSSION: Tuberculosis of the bone, in general usually begins in the cancellous portion of the bones involved. ${ }^{3}$ The route of infection in these cases is either direct inoculation or via blood stream. The presenting symptoms of extraspinal tuberculous osteomyelitis are nonspecific including pain, joint swelling, and decreased range of motion. Systemic symptoms are infrequently seen. Up to $50 \%$ of patients of skeletal tuberculosis do not show concurrent pulmonary disease. ${ }^{1}$ Radiological features of musculoskeletal tuberculosis are non-specific, but may include bone marrow oedema, osteoporosis or lytic lesions. The surrounding tissue may show synovitis, joint effusions, tenosynovitis, soft tissue collections, or myositis. ${ }^{4}$ Histologicaly (Figure 2) the granuloma comprises of epithelioid cells, langhans giant cells and lymphocytes. Diagnosis is often based on more than one test. Being a paucibacillary infection, culture from the infected tissue is seldom positive. Treatment is prompt institution of anti-tubercular drug therapy. Surgical intervention is needed in case of correction of deformities and in halting the progression of lesion. 


\section{CASE REPORT}

CONCLUSION: In conclusion, tuberculosis of navicular bone is rare, though often it is calcaneum ${ }^{2}$ that is most commonly reported in foot. Tuberculosis of the foot is often misdiagnosed due to the uncommon site and lack of awareness. A bone biopsy should always be taken for culture and histological examination. Also understanding of the pathologic and radiologic characteristics of this entity contributes in early diagnosis and prevention of complications.

\section{REFERENCES:}

1. Ya JT, Yu CS. Diagnosis and Monitoring Treatment Response of Skeletal Tuberculosis of Foot by Three-phase Bone Scan: A Case Report. Ann Nucl Med Sci. 2010 Sept; 23(3): 175-180.

2. Dhillon MS, Aggarwal S, Prabhakar S, Bachhal V. Tuberculosis of the foot: An osteolytic variety. Indian J Orthop. 2012 Mar-Apr; 46(2): 206-211.

3. Sandhya KB, Apurba S, Sharada M, Nagaraj E.R. Tuberculosis of Calcaneum: A Rare Case Report. International Journal of Collaborative Research on Internal Medicine \& Public Health. 2012; 4 (8): 1601-1604.

4. Julia D F, Saravana S. Tuberculous osteomyelitis of the midfoot: a case report. Cases Journal. $2009 ; 6859$.

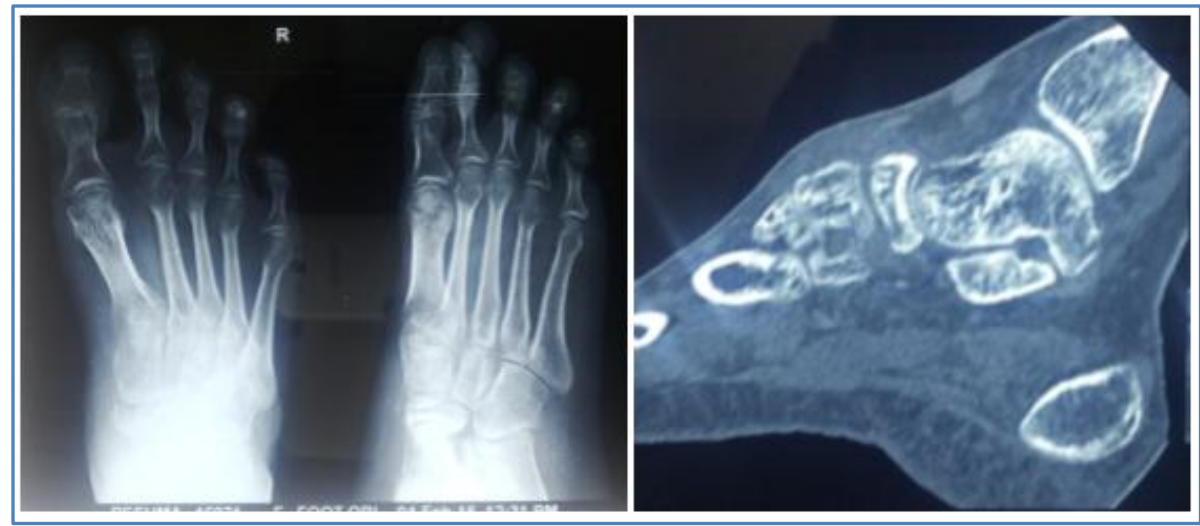

Fig. 1: Lytic lesion in navicular bone

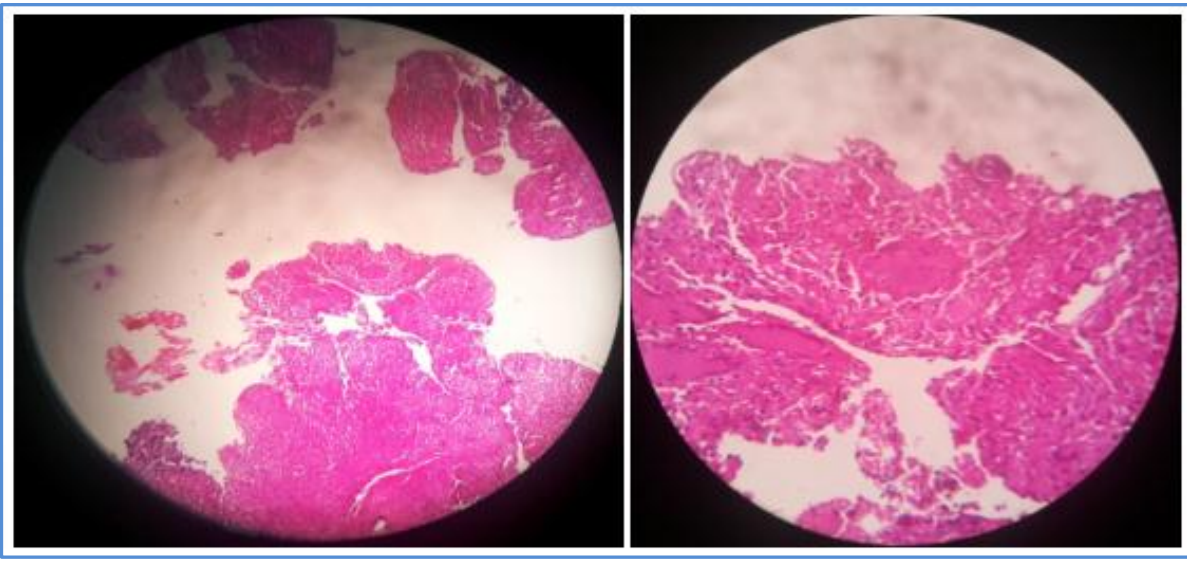

Fig. 2: Granuloma comprising of epitheloid and giant cells 


\section{AUTHORS:}

1. Indudhara P. B.

2. Harish Pai

3. V. V. Yenni

\section{PARTICULARS OF CONTRIBUTORS:}

1. Assistant Professor, Department of Pathology, Subbaiah Institute of Medical Sciences, Shimoga.

2. Associate Professor, Department of Orthopaedics, Subbaiah Institute of Medical Sciences, Shimoga.

FINANCIAL OR OTHER

COMPETING INTERESTS: None
3. Professor \& Head, Department of Pathology, Subbaiah Institute of Medical Sciences, Shimoga.

\section{NAME ADDRESS EMAIL ID OF THE} CORRESPONDING AUTHOR:

Dr. Indudhara P. B, Assistant Professor, Department of Pathology, Subbaiah Institute of Medical Sciences, Shimoga. E-mail: indudharapb@gmail.com

Date of Submission: 23/04/2015. Date of Peer Review: 24/04/2015. Date of Acceptance: 09/05/2015. Date of Publishing: 18/05/2015. 